\section{No independence for French researchers}

Sir - Claude Allègre's intention of "increasing the independence of young researchers" in France is indeed laudable in a country plagued by archaic hierarchical research systems (see Nature 392, 214; 1998). In the current French situation, however, it may well turn out to be an uphill struggle. Allègre's wish goes against a trend towards increasing concentration (and decreasing numbers) of research units that has clearly been favoured by the central administration of the Centre National de la Recherche Scientifique (CNRS) during the past few years.

This has resulted in the elimination of many small but efficient research units that offered good opportunities for young (and not so young) researchers to develop their own research projects without the hindrances inherent in larger bureaucratic entities. This, for example, was my own experience when my research group was squeezed out during the reorganization of Earth sciences research at University Paris 6.

Conversely, this policy has led to the creation of large, heterogeneous conglomerates, which often have little scientific justification but are easier to deal with from a bureaucratic point of view. Under such a system, all researchers, not only young ones, have little or no independence or opportunity to develop really original research projects. The directors of such overblown research 'units' (who may stay in post for as long as 12 years) have absolute control over the funds they receive from CNRS, and therefore wield absolute power. Within such a highly hierarchical system, the so-called "laboratory councils", which are supposed to exercise some control over the scientific policies of research units, are in fact powerless, as their members depend on the goodwill of the director for basic funding.

The problem is further compounded by the fact that most CNRS research units are based in universities, and are often headed by university professors with little time for research. Many of these 'mandarins', as they are usually called in France, have never really accepted the existence of CNRS (an institution founded in 1939!) as an independent research organization, and resent the fact that academic research is no longer exclusively in the hands of university employees.

The result is that CNRS research units are now full not only of young researchers who are debarred from any real responsibility and independence, but also of older 'directors of research' (a CNRS rank which is the equivalent of university professor) who are not in a position to 'direct' anything or, more accurately, to develop original large-scale research projects. If it is to be turned into a reality, Allègre's wish will have to involve a profound change in CNRS policies.

Eric Buffetaut

(Directeur de Recherches,

CNRS (Palaeontology))

16 Cour du Liégat,

75013 Paris, France

e-mail:Eric.Buffetaut@wanadoo.fr

\section{Towards European academic union}

Sir - Recent articles stressed the problems facing universities in Europe, America and Asia, and emphasized their significance as "knowledge producers of modern economies" (Nature 391, 5-9; 1998). But not all countries are in a position to follow the same model, and each country's special circumstances must be taken into account, as must the lack of academic coherence in some universities.

The latter has severely handicapped the prospects for academic and scientific union in Europe, and has also shaped the history of some universities that are both politically and physically far from Brussels. The Spanish universities of La Laguna and Las Palmas de Gran Canaria in the Canary Islands illustrate the problems faced by academic institutions in peripheral regions of Europe.

With Hawaii and the Galapagos, the Canary Islands are among the most important active, volcanic, natural laboratories in the world. One of the first international references to the archipelago was published in Nature more than 100 years ago (Calderon, S. Nature 13, 403-404; 1876) and they are still of great scientific interest. But, despite the socioeconomic importance of the geological resources of the archipelago, geology receives little attention in the islands' academic institutions. There is no specific higher education degree in geology or Earth sciences, and the only department of geology forms part of the faculty of biology.

Given the European Parliament's new capacity to influence scientific and academic policy (see Nature 391, 1; 1998), it is important that these academic imbalances are monitored and corrected. The European Science Foundation has been given the task of examining and advising on research and science policy issues of strategic importance in planning and implementing pan-European initiatives. The foundation could act as the official institution dealing with the relationship between university guidelines, science and their socioeconomic repercussions. (For example, the natural heritage - tourism, natural parks - of the Canary Islands is crucial for the economy of the archipelago; both appropriate knowledge and scientific supervision are therefore needed.)

Much is said about the new economic, monetary and political union of Europe; perhaps it is time to begin defining the basis of academic and scientific union as well.

\section{Jesus Martinez-Frias}

Departamento de Geologia,

Museo Nacional de Ciencias Naturales (CSIC),

c/ Jose Gutierrez Abascal 2,

28006 Madrid, Spain

e-mail:martinezfrias@fresno.csic.es

Jose A. Rodriguez-Losada

Departamento de Edafologia y Geologia,

Facultad de Biologia,

Universidad de la Laguna,

Avda Astrofisico Francisco Sanchez s/n, 38206 La Laguna, Tenerife,

Islas Canarias, Spain

e-mail:jrlosada@ull.es

\section{US teaching methods}

Sir - The continuously improving performance of the United States in science and technology compared to any other country is contrary to the performance of 17-year-old US children (Nature 392, 5; 1998). This raises the question whether there is a need to change and improve standards in US schools.

The basic approach to teaching is different from that in most other countries. During early education in the United States, emphasis is placed on understanding basic concepts, whereas in other countries the emphasis is on memorizing things. These differences may play an important role in creativity and this may be why, when US children become adult, they outperform the rest of the world.

The recent results of the Third International Mathematics and Science Study are worrying. But, before making any changes in US teaching methods, the longterm advantages of existing teaching methods should be studied. Other factors such as the contribution of foreign-born scientists and money spent on science and technology need also to be considered.

Madhusudan G. Soni

Northeast Louisiana University, Monroe,

Louisiana 71209, USA

\section{Correction}

The letter headed "Funding and research performance" (Nature 392, 119; 1998) had five signatories: H. F. Moed, M. Luwel, J. A. Houben, H. Van Den Berghe and E. Spruyt. $H$. Van Den Berghe's name was printed in the wrong format. 


\section{Funding and research performance}

Sir-You reported the finding that the scientific performance of research institutes supported by the UK Biotechnology and Biological Sciences Research Council during 1981-94 was higher than that of a group of 15 British universities (Nature 390, $12 ; 1997)$. But a comparison between the output of universities and other research organizations does not necessarily provide much insight into the factors responsible for observed differences.

We have carried out a study of the effects on research performance of changes in the funding structure of Flemish universities in the 1980s and early 1990s (available on request). In Flanders, as in many countries, universities receive a 'basic allowance' which they are relatively free to spend as they choose. Since the end of the 1970s, this allowance has remained virtually constant.

At the same time, the government has made additional funds available to university research groups on a competitive basis. You have also reported proposals by the Dutch Minister of Education, Culture and Science to transfer DFL500 million (US\$250 million) of university funding to the National Research Council (Nature 390, 9; 1997).

We established for 345 research departments the amount of research funded from the basic allowance, and the support from external funds, expressed in Full Time Equivalents spent on research (FTE-research). We collected bibliometric data and examined trends in publication productivity, defined as the number of articles per FTE-research, as well as citation rates.

We found that, during the 1980s and early 1990s, externally funded research increased by 7 per cent a year. It became increasingly concentrated in a small number of departments, while the distribution between departments of research funded from the basic allowance remained constant. In 1989, 18 departments $-5 \%$ of the total accounted for $37 \%$ of the externally funded research capacity, but only $11 \%$ of the 'basic' research capacity.

Departments with a high international impact have profited much more from external funding than groups with a lower standing. The general aim in Flanders, to introduce more competition into the allocation of funds for academic research, has been successful. But overall productivity has remained constant, mainly because the publication output of the departments with the strongest increase in externally funded research decreased significantly, whereas the ratio of junior to senior scientists increased dramatically, from 1.6 to 3.9 .

If these trends continue, a situation may emerge in Flanders in which the research base, especially tenured personnel, normally provided by a university out of its own resources, becomes too small for externally funded research activities. Furthermore, there appears to be a limit to the extent to which control over research funds can be transferred from universities to external funding agencies without a loss of productivity. If this process is pushed too far, the productivity of the system as a whole may decline, as the conditions in which senior scientists have to work particularly in departments of high international standing - may make it impossible to maintain the potential quality of their research or to train young scientists.

Also, the increasing importance of external competitive funding may lead to an imbalance in the funding system unless universities develop their own somewhat risky internal research policies, relying more than normally upon external funding patterns. This is illustrated by the fact that the faculty of medicine at the Catholic University of Leuven, which has a strong internal research policy, showed the highest impact and productivity of all faculties in the study.

\section{H. F. Moed}

Centre for Science and Technology Studies,

Leiden University, PO Box 9555 ,

2300 RB Leiden,

The Netherlands

e-mail:moed@cwts.leidenuniv.nl

\section{Luwel}

Ministry of the Flemish Community,

Brussels, Belgium

J. A. Houben

H. Van Den Berghe

Catholic University of Leuven,

Leuven, Belgium

E. Spruyt

University of Antwerp,

Antwerp, Belgium

\section{A different view}

Sir - Colin Macilwain's News article of 22 January and your leading article of 29 January (Nature 391, 311-312 \& 419; 1998) offer one perspective on the US Department of Energy's Academic Strategic Alliances Program (ASAP). As the senior research administrators of the five universities involved, we offer another.

ASAP research will advance and accelerate high-performance computer simulation of physical systems. Researchers at our universities will develop computational algorithms, software and visualization tools for some of the world's most powerful computers and apply them to challenging problems in science and engineering, many of them important in industry. In the course of this work, graduate students and postdocs will be trained in advanced technologies that will have far-reaching applications throughout society.
The awards to our universities derived from a peer-reviewed competition among 22 proposals selected from 48 preproposals by many of the country's leading academic institutions. All the ASAP research is unclassified and in wellestablished academic fields, many of them (including the explosive shocks and turbulence mentioned in your leading article) covered by leading journals such as Nature. All our seminars are open to the public and our results will be published in the open literature.

One of the applications of ASAP research will be to the important national goal of Science Based Stockpile

Stewardship. This Department of Energy programme, which has strong bipartisan support in the government, will contribute to national security as the United States continues its halt of nuclear testing and so complies with the Comprehensive Test Ban Treaty.

Further details of our ASAP research can be found on the Web by following the links at http://www.llnl.gov/asci-alliances/ centers.html

Richard C. Alkire

(Vice Chancellor for Research)

University of Illinois at Urbana-Champaign

Richard K. Koehn

(Vice President for Research)

University of Utah

Steven E. Koonin*

(Vice President and Provost)

California Institute of Technology,

Mail Code 206-31,

Pasadena, California 91125, USA

e-mail:staceys@cco.caltech.edu

Charles Kruger

(Vice Provost and Dean of

Research and Graduate Policy)

Stanford University

Robert J. Zimmer

(Associate Provost for

Research and Education)

University of Chicago

${ }^{*}$ Corresponding author 